\title{
Development Priorities: \\ The Relative Benefits of Agricultural Growth
}

\author{
Fabio Monteforte \\ Mathan Satchi \\ Jonathan Temple
}

Discussion Paper 19 / 716

21 June 2019

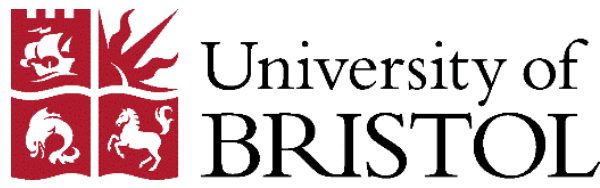

Department of Economics

University of Bristol

Priory Road Complex

Bristol BS8 1TU

United Kingdom 


\title{
Development Priorities: \\ The Relative Benefits of Agricultural Growth
}

\author{
Fabio Monteforte \\ University of Messina \\ Mathan Satchi \\ University of Kent \\ Jonathan Temple \\ University of Bristol
}

June 21, 2019

\begin{abstract}
Should agriculture or non-agriculture be a priority for development? We revisit this longstanding and intractable question using a two-sector, three-factor dynamic model with an asymptotic balanced growth path. The model allows a forward-looking assessment of development priorities based on lifetime welfare. A comparison of sector-specific productivity gains indicates that gains in non-agriculture are often more valuable, even when agriculture is initially the largest sector in terms of employment. We discuss the robustness of this result, including the roles of capital intensity, the discount rate, and taxes on profits in influencing the rates of investment and structural transformation.
\end{abstract}

JEL Classifications: O40

Keywords: Structural transformation, agriculture, development policies, investment

Corresponding author email: jon.temple@bristol.ac.uk. This research was funded by ESRC/DFID award no. ES/J009601/1, 'Structural Change and Productivity Growth in Africa', principal investigator Margaret McMillan. A preliminary version was presented at the Arthur Lewis centenary conference in Manchester, a DEGIT conference in Nottingham, and an MMF conference in Bath. We are grateful to those audiences for comments, with the usual disclaimer. 


\section{Introduction}

Should developing country governments and aid donors make agriculture their first priority, or manufacturing and services? There are many possible considerations, and their relative importance is unknown. The context could matter in ways that are hard to establish. For reasons like these, it seems probable that researchers will never arrive at a definitive answer. Textbooks on development highlight some of the considerations, but refrain from drawing conclusions. Yet, in practical terms, the question is one that ultimately cannot be avoided: an answer of some form will be implicit, at least, in a range of development policies and decisions.

The question is difficult for a number of reasons, beyond the sheer range of possible considerations. First, the overall effect of sector-specific development policies is inherently a general equilibrium question. Second, it is also a dynamic question, because the responses to policies, and their effects, will vary over time. Third, although a traditional framing of development priorities would examine the effect of policies on the overall growth rate, that approach is incomplete. Different growth scenarios will often be associated with different paths for the capital stock. In turn, the scenarios will differ in how much consumption is foregone along the equilibrium path. This suggests that analysis of growth effects should be supplemented by a welfare analysis, based on the lifetime utility of households.

With these points in mind, this paper uses a dynamic general equilibrium approach to study effects on lifetime welfare. We describe a two-sector, three-factor growth model with an asymptotic balanced growth path and endogenous saving. At each instant, households have Stone-Geary preferences over the two goods. The saving decision is otherwise specified as in the conventional Ramsey model. Structural transformation is influenced partly by exogenous technical progress in the two sectors, partly by capital accumulation, and partly by the interaction between a growing population and a fixed stock of land.

If productivity growth in the non-agricultural sector is sufficiently fast, the model yields an asymptotic balanced growth path. The employment share of the agricultural sector approaches zero asymptotically, so that the two-sector structure ultimately gives way to the one-sector Ramsey model. An advantage of the model is that we can obtain a structural transformation and (asymptotic) balanced growth without assuming knife-edge restrictions on parameters or symmetric production technologies. We introduce a computational device that helps to solve the model numerically without linearization or other approximations, even though the balanced growth path is approached only asymptotically.

Using the model, we ask whether a step change in agricultural total factor productivity (TFP) is more or less beneficial, in welfare terms, than a similar step change in non-agricultural productivity. We could think of these step changes as reflecting, say, sectorspecific investments in rural or urban infrastructure. The approach is stylized and reducedform, but it helps to isolate some of the relevant trade-offs. In our simulations, we consider economies in which the agricultural sector is initially the largest in terms of employment. Other things equal, this suggests agricultural productivity increases will be especially benefi- 
cial. The obvious direct effect of higher TFP on output will be reinforced by dynamic effects, because higher productivity in either sector makes available extra resources for investment.

This is not the whole story, however. First, if a developing economy is experiencing a conventional structural transformation, the non-agricultural sector will be expanding over time. As it expands, the direct benefits of a productivity improvement in that sector will mount. Second, in a small open economy setting, the assumption that agriculture is less capital intensive has implications for capital accumulation. A productivity gain in agriculture causes that sector to expand, but since it is less capital intensive than non-agriculture, the aggregate demand for capital may fall. In a model with endogenous saving, this restrains capital accumulation. If instead the capital-intensive sector is made the priority for productivity gains, this leads to transitional dynamics with faster capital accumulation and faster growth in wages and capital income.

In the model we consider, it is the overall balance of these effects which influences whether agricultural or non-agricultural productivity improvement is most beneficial for lifetime welfare. The conclusion will be influenced partly by the discount rate and partly by the speed of structural transformation. One of our findings is that a forward-looking assessment may be enough to tip the balance towards non-agriculture in setting priorities, even when agriculture is initially the largest sector in terms of employment. The result is not reversed even if we reduce the rates of sector-specific technical progress, to slow down structural transformation.

But the balance can be tipped by other ways of slowing down structural transformation. One route is to assume a higher discount rate, corresponding to more impatient households. This matters for two reasons. First, it gives more weight in the welfare calculation to nearterm outcomes, and the near term is when the agricultural sector is largest. Second, with a higher discount rate, households save less. This lowers investment, slows down the rate of structural transformation, and lowers the relative benefits of non-agricultural productivity improvement.

A second route is to assume that profits are taxed, either by the formal tax system, or perhaps through corruption and other forms of institutional weakness, such as a risk of expropriation. This change again slows down capital accumulation and the rate of structural transformation, helping to tip the balance back towards the agricultural sector as a priority. When this effect is large, the rate of structural transformation is in the empirically relevant range, but the model implies gross investment rates that are lower than we see in the data.

To avoid misinterpretation, we emphasize that these findings do not, and cannot, resolve the larger debate. There are many considerations that are omitted from the analysis, such as rural off-farm employment (Foster and Rosenzweig 2008), human capital (Wingender 2015), public capital (Felice 2016), and the potential role of agricultural productivity growth in creating a domestic market for non-agricultural goods. Nor do we give any consideration to the costs and feasibility of achieving productivity improvements in a given sector, which would be needed for a policy analysis, along with an analysis of countryspecific circumstances (Dercon and Gollin, 2014). Our contribution is more limited, namely 
to clarify trade-offs and general equilibrium mechanisms that can help to inform the wider debate. Among these, we emphasize the role of the speed of structural transformation when forward-looking conclusions are drawn about development priorities.

The remainder of the paper has the following structure. The next section provides some background discussion and context. Section 3 investigates the rate of structural transformation in eleven sub-Saharan African economies, using the new data of de Vries et al. (2015). Section 4 introduces the model. Section 5 sets out the assumptions used in the simulations, and section 6 presents the simulation results. Section 7 concludes.

\section{Background}

Discussion of the relative importance of agriculture and non-agriculture has a long history in development economics. The debate emerged in the 1950s, partly through the work of Arthur Lewis, the 1979 Nobel Laureate in economics. Lewis is often seen as a rigid believer in rapid industrialization driven by investment in manufacturing, aided by government planning. But his biographers emphasize that his views were more complicated, as reflected in his work in the early 1950s as an adviser to the Gold Coast (present-day Ghana). In his 1953 report on industrialisation in the Gold Coast, he wrote that "The most certain way to promote industrialisation in the Gold Coast is to lay the foundation it requires by taking vigorous measures to raise food production per person engaged in agriculture... To the extent to which industrialization is financed from domestic savings, it is, in the ultimate analysis, the farmers who provide the wherewithal" (Lewis 1953, quoted in Mosley and Ingham, pp. 149-150). In line with this, he recommended spending on agricultural research and rural extension services.

Was this good advice? More than sixty years later, the question remains unresolved. Contrary to Lewis, the analysis below will suggest that agricultural productivity gains in an open economy do not always accelerate capital accumulation. The reason is that, in a small open economy setting, an agricultural productivity gain leads that sector to expand and the non-agricultural sector to contract. When agriculture is assumed to have lower capital intensity than non-agriculture, this effectively reduces the aggregate demand for capital. The capital-output ratio then takes longer to converge to its steady-state value. ${ }^{1}$

This result emerges via the assumption of endogenous saving. The effect of increased agricultural productivity on saving is limited because, if households could see benefits from additional saving, they would have been saving more in any case. This leaves the question to be determined largely by the direct benefits of productivity improvement. Here, we show that the rate of structural transformation plays a critical role. If structural transformation is taking place, productivity improvement in non-agriculture is sometimes more beneficial than in agriculture. Put differently, the conventional argument that the largest sector matters

\footnotetext{
${ }^{1}$ This is an example of how a dynamic general equilibrium approach can inform the analysis of these questions. Dercon and Gollin (2014, p. 487) note that the debate on agriculture's role is underdeveloped, although they emphasize the lack of attention to the costs and opportunity costs of agriculture-specific policies.
} 
most can be overturned when the structure of the economy is changing over time and we make a forward-looking assessment.

Our assumption of a small open economy setting helps to simplify the analysis, but could be criticized. Gollin (2010, p. 3835) notes that most food in sub-Saharan Africa is produced within the country where it is consumed; see also Gollin et al. (2007). But imports are not unknown, even in the poorest countries (Mason et al. 2011). For example, in Malawi the most important staple food is maize, and about $40 \%$ of marketed maize is imported from nearby countries. Almost all wheat and rice consumed in Malawi is imported. More systematic evidence is provided by Mundlak and Larson (1992), who studied price variation in 58 countries over 1968-78. They found that variations in the world prices of agricultural commodities are the dominant component in the variation of domestic prices. Their sample included only a few sub-Saharan African countries, but openness is likely to have increased since the time period of their analysis. Hence, the question of whether closed or open economy models are likely to be the best approximation can be considered unresolved.

A secondary contribution of this paper is to show that an open economy model generates more realistic paths for key variables than closed one-sector models. The transitional dynamics of the one-sector Ramsey model with isoelastic utility are known to be problematic, and at variance with observed growth experiences. In the early stages of a transition, the Ramsey model generates a sharp decline in the return to capital, together with very high initial productivity growth, neither of which seem to be observed in the data. King and Rebelo (1993) provide one well-known demonstration, using a version of the model calibrated to the post-war growth of Japan. The more general problems of the Ramsey model are discussed in Barro and Sala-i-Martin (2004, pp. 116-118). They emphasize that the transitional dynamics of the Ramsey model become plausible only if capital is defined broadly, with an aggregate output-capital elasticity that substantially exceeds capital's share of value added.

Several authors, notably Robertson (1999), have suggested that a two-sector economy can remedy these problems, especially when that economy is open to trade. In trade theories, factor prices are sometimes independent of factor supplies, so the return to capital will be invariant to the capital stock. As capital is accumulated, reallocation across sectors maintains the return to capital at a constant level. ${ }^{2}$ In more general models, the return to capital is likely to change over time, but reallocation across sectors will limit the extent of its decline.

Our two-sector, three-factor structure does much to render the solution paths more plausible. We can do this relatively simply, because we consider a small open economy in which both goods are traded. In this case, goods prices are exogenous (they are set by world markets) and the analysis becomes especially straightforward. Preferences still matter, but only in influencing the intertemporal decision on how much to save. In contrast, much of

\footnotetext{
${ }^{2}$ This result was emphasized in Leamer (1987), and plays a central role in Ventura (1997) and other work on growth which draws on Heckscher-Ohlin models; see Ventura (2005) and chapter 19 of Acemoglu (2009). Feenstra (2004) provides a textbook discussion of 'factor price insensitivity' results.
} 
the literature on structural transformation assumes a closed economy. That approach may be natural for the historical US, but less clearly applies to present-day developing countries. ${ }^{3}$

We adopt Stone-Geary preferences, in which the elasticity of intertemporal substitution is low when expenditure is low. In the one-sector case, Stone-Geary preferences are well known to generate more realistic growth paths. Under these preferences, investment may be deferred, and hence Christiano (1989) calls this the 'slow convergence model'. The large literature includes Rebelo (1992), King and Rebelo (1993), Ben-David (1998), Kraay and Raddatz (2007), Ohanian et al. (2008) and Steger (2009). Under these preferences, the elasticity of intertemporal substitution is increasing in the level of consumption, which is consistent with much of the microeconometric literature on consumption even for developed countries: see Attanasio and Browning (1995), Blundell, Browning and Meghir (1994) and Crossley and Low (2011). The theoretical importance, and wide-ranging implications, of a variable intertemporal elasticity of substitution have been emphasized by Bliss $(2007,2008)$. In the aggregate data, there is clear evidence that rates of saving or investment are lower in poor countries than in rich ones, as documented in Kraay and Raddatz (2007) and Sachs (2005), among others.

The literature on multi-sector models with non-homothetic preferences is extensive, but generally uses closed economy models. ${ }^{4}$ Among previous work, the structure of our model is especially close to Roe et al. (2010). They consider dynamic general equilibrium models of small open economies with endogenous saving and Stone-Geary preferences. There are two key differences. Their approach to obtaining balanced growth differs, and they do not consider the question of development priorities, the central focus of this paper. ${ }^{5}$

In all our various experiments, we treat technical progress as exogenous. This choice of emphasis is broadly consistent with the findings of Schelkle (2014): using results from development accounting, he finds that episodes of international catching up (relative to the United States) are primarily associated with factor accumulation rather than changes in relative efficiency. This implies that models with exogenous rates of technical progress, but endogenous investment, remain of interest.

Part of the background to our paper is the perception that structural transformation has been delayed in Africa in particular, or has worked against raising aggregate productivity. McMillan and Rodrik (2012) argue that recent changes in sectoral structure in Africa have sometimes favoured sectors with relatively low productivity at the margin. Our model assumes costless mobility of capital and labour across sectors, but could be generalized to allow for distortions. If the marginal products of labour or capital were higher in nonagriculture, as is sometimes assumed, that would tend to increase the relative benefits of productivity improvements in non-agriculture.

\footnotetext{
${ }^{3}$ Papers on growth in open, multi-sector economies include Connolly and Yi (2015), Cuñat and Maffezzoli (2004), Matsuyama (1992), Święcki (2017), Uy et al. (2013) and the book by Roe et al. (2010).

${ }^{4}$ See, for example, Kongsamut et al. (2001), Irz and Roe (2005), Gollin et al. (2007), Alonso-Carrera and Raurich (2015) and the book by Bertola et al. (2006). Hayashi and Prescott (2008) consider both closed and open economy models.

${ }^{5}$ Roe et al. (2010, p. 81) ensure balanced growth in a small open economy by assuming land-augmenting technical progress at a particular rate.
} 


\section{Data}

The rate of structural transformation will play a key role in what follows. With this in mind, we introduce a simple measure of this rate, which can be compared across countries and with later simulation results. Since our focus is primarily on low-income countries, we estimate the speed of transformation for eleven sub-Saharan African countries since the 1960s. To do this, we use the African Sector Database compiled by de Vries et al. (2015). The eleven countries in the database together account for about 70 per cent of the region's GDP.

Figure 1 shows the path of the agricultural employment share for these eleven countries over 1961-2011. In figure 2, for greater clarity, we show the same data in separate panels. It is clear that the eleven countries vary greatly in the pace of structural transformation, and in one case (Nigeria) there has been a major reversal in sectoral structure, and hence slow change over the period as a whole.

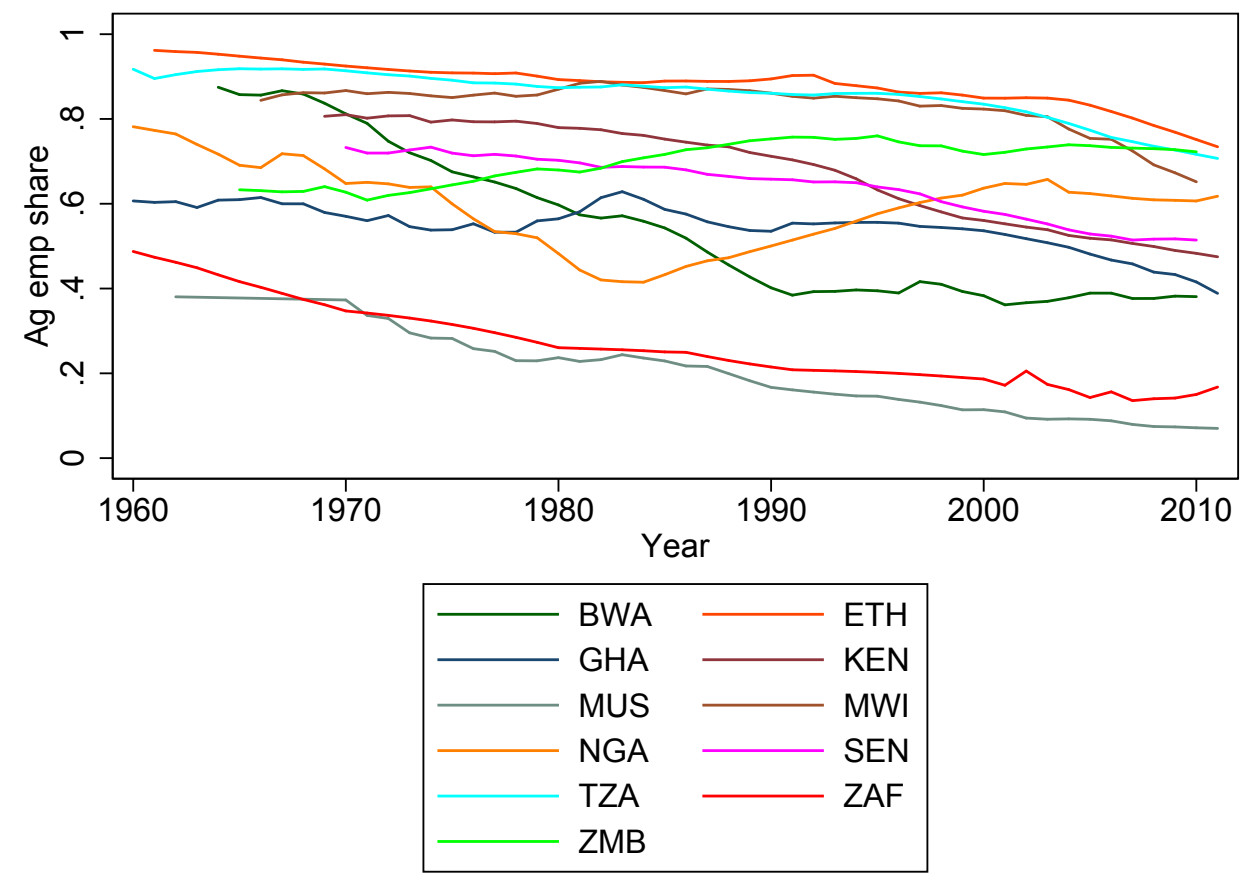

Figure 1: Agricultural employment shares for 11 SSA countries

It will be useful to have a single numerical measure of the rate of structural transformation. We make the assumption that the employment share of agriculture $\ell_{a}$ declines geometrically, given by the equation $\dot{\ell}_{a}=-\eta \cdot \ell_{a}$. We use $100 \eta$ as our country-specific measure of the rate of structural transformation, obtained by regressing the log employment share on a time trend:

$$
\log \ell_{a}(i, t)=\mu(i)-\eta(i) \cdot t+\varepsilon(i, t)
$$

where $i$ is the country index and $t$ is time. The higher is $\eta$, the faster the rate of structural transformation. The higher is the $R^{2}$ of this regression for a given country, the better is our 


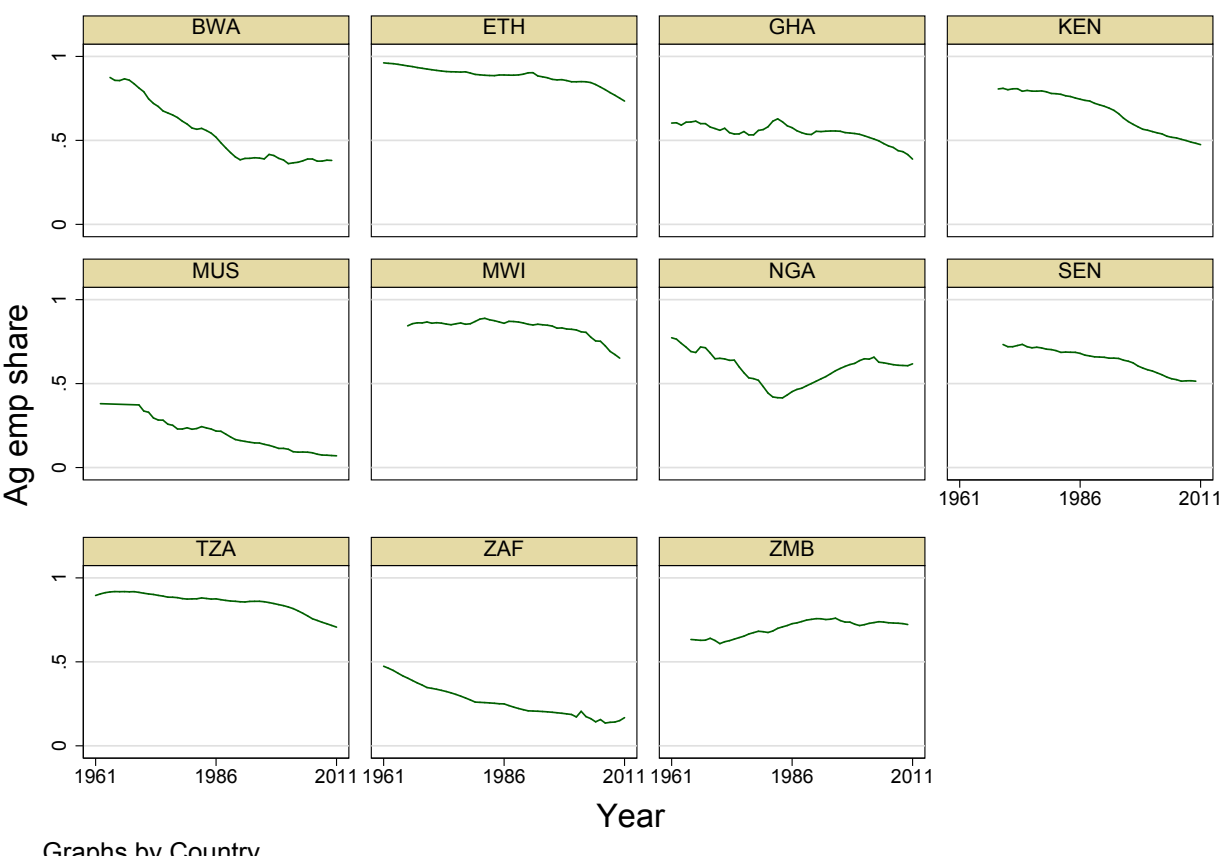

Figure 2: Agricultural employment shares, displayed separately

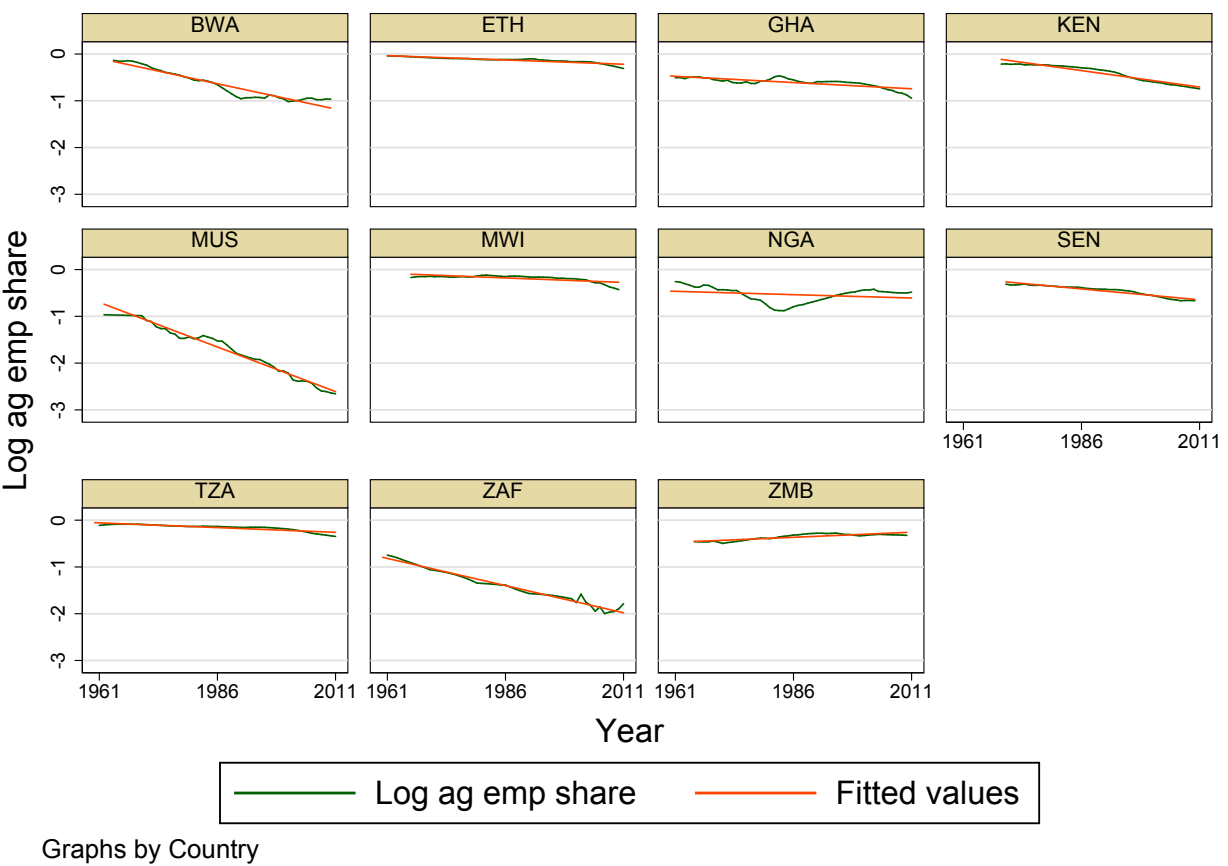

Figure 3: Log agricultural employment shares, with time trends

assumption that the employment share declines geometrically.

Figure 3 plots the logarithm of the employment share, together with the fitted line from a regression of the log employment share on a time trend. For some of the countries, the 
regression fits well, which suggests that geometric decline of the agricultural employment share is a good approximation. We take the slope of this regression, multiplied by 100 , as our measure of the rate of structural change, $100 \eta$. The estimates are presented in Table 1 , ranked from fastest (Mauritius) to slowest (Zambia).

\begin{tabular}{l|c|r}
\hline \hline Country & $100 \eta$ & Std Err \\
\hline MUS & 3.81 & 0.099 \\
ZAF & 2.32 & 0.054 \\
BWA & 2.17 & 0.098 \\
KEN & 1.41 & 0.06 \\
SEN & 0.94 & 0.044 \\
GHA & 0.53 & 0.06 \\
TZA & 0.41 & 0.03 \\
MWI & 0.39 & 0.058 \\
ETH & 0.36 & 0.024 \\
NGA & 0.29 & 0.152 \\
ZMB & -0.43 & 0.042 \\
\hline \hline
\end{tabular}

Table 1: Rates of structural transformation

\section{The model}

In this section, we describe the model. We consider a small open economy with two sectors, in which the outputs of both sectors can be traded on world markets, and hence their relative price is determined by world prices. We assume there is a rural sector which produces an agricultural good, and co-exists with an emerging urban 'non-agricultural' sector that produces a composite good. ${ }^{6}$ The two sectors, agriculture and non-agriculture ('manufacturing'), will be denoted by the subscripts $a$ and $m$ respectively. We treat the non-agricultural good as the numéraire, and the fixed relative price of the agricultural good is denoted by $p_{a}$.

Time is continuous, with an infinite time horizon. There is no uncertainty, allowing us to focus on the medium-run transitional dynamics as they unfold over decades. We model the optimization problem of a representative household that cannot borrow or lend internationally. We consider the population as distributed among identical households or dynasties, which grow in size at a constant rate $n$, so $L(t)=L(0) \exp (n \cdot t)$. Each member of the household supplies one unit of labour inelastically.

The representative household's objective function is given by:

$$
\int_{0}^{\infty} v\left(x(t), p_{a}\right) \cdot L(0) \cdot \exp (-(\rho-n) \cdot t) d t
$$

\footnotetext{
${ }^{6}$ At constant prices, this composite good can be interpreted as a bundle of manufacturing goods and services. To keep the analysis simple, we abstract from the distinction between manufacturing and services in what follows.
} 
where $v\left(x(t), p_{a}\right)$ is indirect utility, $x(t)$ is nominal expenditure and $p_{a}$ is the relative price of the agricultural good. $\rho>0$ is the subjective discount rate. In what follows, we sometimes suppress the time argument when there is no loss of clarity.

The representative household chooses the path of nominal expenditure $x$ to maximize lifetime welfare, given an equation for the evolution of assets and a no-Ponzi condition. The household earns a return on assets denoted by $r$ and the stock of assets per capita is denoted $a$. The evolution of assets per capita is given by:

$$
\dot{a}=w+r \cdot a-x-n \cdot a
$$

where $w$ is the wage. A standard no-Ponzi condition ensures that the lifetime budget constraint is well defined:

$$
\lim _{t \rightarrow \infty}\left[a(t) \cdot \exp \left(-\int_{0}^{t}(r(s)-n) d s\right)\right] \geq 0
$$

We will assume that intratemporal preferences are Stone-Geary. The indirect utility function will be:

$$
v\left(x(t), p_{a}\right) \equiv \frac{1}{1-\sigma}\left[\frac{x(t)-p_{a} q}{p_{a}^{\gamma}}\right]^{1-\sigma}
$$

These preferences are a special case of the class that Alder et al. (2019) call 'intertemporally aggregable' (IA). IA preferences have the attractive property that intertemporal decisions do not depend on the distribution of income across households. The asymptotic elasticity of intertemporal substitution is given by $1 / \sigma$, where $\sigma \neq 1$ and we assume throughout that $\rho>n+(1-\sigma) g_{m}$ so that lifetime utility is bounded, where $g_{m}$ is the growth rate of labour-augmenting efficiency in the non-agricultural sector.

Our special case corresponds to a Stone-Geary intratemporal utility function $\left(c_{a}-\right.$ $q)^{\gamma} c_{m}^{1-\gamma}$ where $c_{a}$ is consumption per capita of the agricultural good, $c_{m}$ is consumption per capita of the non-agricultural good, $0<\gamma<1$, and the subsistence parameter $q>0$ ensures that the budget share of the agricultural good declines as total consumption expenditure rises. $^{7}$ If $q$ is high enough, these preferences are likely to restrain saving in the early years of a transition. This seems plausible for low-income countries, and is consistent with evidence that investment rates in sub-Saharan African countries are not high (Melina and Portillo 2018).

We can write the current-value Hamiltonian for the household's problem as:

$$
H=v\left(x, p_{a}\right)+\lambda(w+r \cdot a-x-n \cdot a)
$$

\footnotetext{
${ }^{7}$ As is standard in models with these preferences, we assume productivity is sufficiently high that consumption of the agricultural good is always higher than the subsistence level.
} 
The static and dynamic conditions for the optimality of a candidate interior solution are:

$$
\begin{aligned}
& \frac{\partial H}{\partial x}=\frac{\partial v}{\partial x}-\lambda=0 \\
& \frac{\partial H}{\partial a}=(\rho-n) \lambda-\dot{\lambda}=(r-n) \lambda .
\end{aligned}
$$

together with the transversality condition

$$
\lim _{t \rightarrow \infty}[\exp (-(\rho-n) \cdot t) \cdot \lambda(t) \cdot a(t)]=0
$$

Following Acemoglu (2009, pp. 294-6) it can be shown that household maximization, including the transversality condition (6), implies that the no-Ponzi condition (3) in the original problem will hold with equality.

For present purposes, rather than derive an explicit dynamic equation in nominal consumption expenditure $x(t)$, it will be sufficient to work with the costate variable $\lambda(t)$. This has a direct interpretation as the marginal utility of wealth.

We now turn to the production equilibrium, which is the outcome of decisions by perfectly competitive firms, using production technologies with constant returns to scale. Nonagricultural firms produce output using capital $K_{m}$ and labour $L_{m}$. Agricultural firms produce output using capital $K_{a}$, labour $L_{a}$ and land $R_{l}$. As we discuss later, the role of the fixed factor, land, ensures that the agricultural sector never closes down completely, which simplifies the numerical solution of the model.

The production technologies are given by:

$$
\begin{aligned}
Y_{a} & =G\left(K_{a}, A_{a} \cdot L_{a}, R_{l}\right) \\
Y_{m} & =F\left(K_{m}, A_{m} \cdot L_{m}\right)
\end{aligned}
$$

where $A_{a}$ and $A_{m}$ are the sectoral levels of labour-augmenting efficiency, growing at the (exogenous and constant) rates $g_{a}$ and $g_{m}$ respectively. Aggregate output is given by:

$$
Y \equiv p_{a} \cdot Y_{a}+Y_{m}
$$

Since we restrict attention to cases where the relative price $p_{a}$ is constant over time, $Y$ can also be taken as a measure of constant-price real GDP, although our focus will be effects on welfare rather than on real GDP.

We assume that labour is perfectly mobile between the two sectors, and in each sector, receives a wage equal to its marginal product. For the sectoral equilibrium at each instant, wages are equalized:

$$
\begin{aligned}
w_{m} & =w_{a} \\
F_{L_{m}}^{\prime} & =p_{a} \cdot G_{L_{a}}^{\prime}
\end{aligned}
$$


All capital will be fully utilized in equilibrium, so $K_{a}$ and $K_{m}$ sum to the total capital stock $K$. Capital can move freely between sectors, so that returns are equalized at each instant:

$$
F_{K_{m}}^{\prime}=p_{a} \cdot G_{K_{a}}^{\prime}
$$

The role of land in the model is worth noting. Without land, the economy we have described would be a dynamic version of the $2 \times 2$ trade model. For dynamic analysis, that model has the drawback that the economy will be completely specialized in one sector or the other for some ranges of the capital-labour ratio. This implies that the model would switch regimes over time. Including a role for land in agriculture has the advantage that, although agriculture's share of employment and output will approach zero asymptotically, the sector will never close down completely. This means that the economy can be described by the same set of equations throughout, which simplifies the numerical solution of the model.

We now consider the use of capital, which firms rent from households. Given fixed prices, firms equate the value of the marginal product of capital to the sum of the interest rate and depreciation, in the usual way, and hence:

$$
F_{K_{m}}^{\prime}=p_{a} \cdot G_{K_{a}}^{\prime}=r+\delta
$$

Since there is no international borrowing or lending, the capital stock per worker $k \equiv K / L$ is equal to assets per worker, and hence $k=a$ at every instant. Combined with equation (2), capital per worker will evolve as:

$$
\dot{k}=y-x-(n+\delta) \cdot k
$$

and equation (5) for the evolution of the costate can be rewritten as:

$$
\frac{\dot{\lambda}}{\lambda}=\rho-\left(f^{\prime}\left(k_{m}\right)-\delta\right)
$$

where $k_{m} \equiv K_{m} /\left(A_{m} \cdot L_{m}\right)$ and $f\left(k_{m}\right) \equiv F\left(k_{m}, 1\right)$ is the non-agricultural production function in effective worker terms. Note that the two differential equations just stated link the production equilibrium to the household side of the model, partly through equation (4).

We now discuss the balanced growth path. As is well known, balanced growth paths in multi-sector models often require a knife-edge parameter restriction, or restrictions on the production technologies (for example, Kongsamut et al. (2001) and Ngai and Pissarides (2004)). Our model avoids this, as it implies that the non-agricultural sector ultimately dominates. This outcome will require an inequality condition on parameters, rather than a knife-edge restriction. It allows us to specify production technologies with output-capital elasticities that differ between the two sectors, which is consistent with the evidence in Eberhardt and Teal (2013b).

Under an assumption stated later, the economy will converge to an asymptotic balanced 
growth path in which the agricultural employment share approaches zero. Output per worker and capital per worker grow at $g_{m}$, the rate of labour-augmenting technical progress in non-agriculture. When needed, we can normalize all the endogenous per capita variables in effective worker terms, dividing them by $A_{m}$. The normalized costate variable $\hat{\lambda}$ is defined by $\hat{\lambda} \equiv \lambda A_{m}^{\sigma}$.

For the simulations, we adopt a Cobb-Douglas production function in agriculture, which has often been adopted in the empirical literature. ${ }^{8}$

$$
Y_{a}=X_{a} \cdot R_{l}^{\alpha} \cdot K_{a}^{\beta} \cdot\left(A_{a} \cdot \ell_{a} \cdot L\right)^{1-\alpha-\beta}
$$

Given evidence, including Chirinko (2008) and Knoblach et al. (2019), that the elasticity of substitution is less than one for the US economy, we adopt a CES production function in non-agriculture:

$$
Y_{m}=X_{m}\left(\delta_{p} K_{m}^{-\nu}+\left(1-\delta_{p}\right)\left(A_{m} \cdot\left(1-\ell_{a}\right) \cdot L\right)^{-\nu}\right)^{-\frac{1}{\nu}}
$$

where the elasticity of substitution between capital and labour is given by $\sigma_{K L} \equiv 1 /(1+\nu)$.

The agricultural sector disappears asymptotically, and the ratio of land to labour in that sector approaches infinity. With this in mind, for the purpose of the numerical solution, it will be useful to work with a transformation of the land variable, and an additional normalization variable with a known path. The transformation of the land variable is given by:

$$
k_{l} \equiv R_{l} \cdot A_{a}^{\frac{1-\alpha-\beta}{\alpha}} /\left(A_{m}^{\frac{1-\beta}{\alpha}} \cdot \ell_{a} \cdot L\right)
$$

and the additional normalization variable $z$ is given by:

$$
z \equiv A_{a}^{\frac{1-\alpha-\beta}{\alpha}} /\left(A_{m}^{\frac{1-\beta}{\alpha}} \cdot L\right)
$$

These two equations together imply:

$$
k_{l} \cdot \ell_{a}=R_{l} \cdot z
$$

while, after some algebra, the agricultural production function (12) can be rewritten in normalized terms as:

$$
y_{a}=X_{a} \cdot k_{l}^{\alpha} \cdot k_{a}^{\beta}
$$

where $y_{a} \equiv Y_{a} /\left(A_{m} \ell_{a} L\right)$ and $k_{a} \equiv K_{a} /\left(A_{m} \ell_{a} L\right)$. The transformed land variable $k_{l}$ will asymptotically approach a finite constant, even though the ratio of land to labour in agriculture approaches infinity as the agricultural employment share approaches zero. The use of a transformed land variable then allows us to solve the model in a simple way.

Note that the dynamic path of $z$ is exogenous and known. Based on its definition,

${ }^{8}$ Block (2014, p. 377) describes the assumption of a constant returns Cobb-Douglas production function in agriculture as 'repeatedly validated' in empirical studies. 
consider the following inequality restriction on parameters:

$$
\left(\frac{1-\alpha-\beta}{\alpha}\right) g_{a}<\left(\frac{1-\beta}{\alpha}\right) g_{m}+n
$$

where $n, g_{m}$ and $g_{a}$ are the growth rates of population, $A_{m}$ and $A_{a}$, respectively. When this inequality holds, $z$ will asymptotically converge to zero:

$$
\lim _{t \rightarrow \infty} z(t)=0
$$

Since $R_{l}$ is fixed and $z$ follows an exogenous path, asymptotically approaching zero at a known rate, so will the product of $k_{l}$ and $\ell_{a}$ as implied by equation (16). Since $k_{l}$ approaches a finite constant, $\ell_{a}$ approaches zero. The relative importance of agriculture declines and, asymptotically, the growth path will approach that of the standard one-sector Ramsey model with efficiency growth at rate $g_{m}$.

Note that we do not explicitly model the price of land. This asset price is a jump variable, which at time zero will jump on to an equilibrium path. Along this path, overall returns from holding land will be continuously equal to returns on other assets, given capital gains or losses on the value of the land (see, for example, Roe et al. 2010, pp. 81-82). But since the intertemporal decisions and static allocations of interest to us are independent of the price of land along the equilibrium path, we do not need to model the price explicitly. The land price path implicit in a solution for the other variables could be computed if needed.

\section{Simulation assumptions}

In the simulations, we select parameters to match relevant characteristics of sub-Saharan African countries in the Africa Sector Database (ASD) of de Vries et al. (2015), around 2010; see in particular their Appendix Table C5. We are not seeking to match historical data for any individual country, or to make predictions about future growth, since the model we adopt is too stylized for that to be worthwhile.

We consider an economy in which agriculture initially employs $56 \%$ of the labour force, based on the median value for the eleven ASD countries in 2010. We set population growth $n=0.027$ by calculating the annual population growth rate over 2000-2010 for the ASD countries, the median of which is $2.7 \%$. The population data we use are taken from version 9.1 of the Penn World Table (Feenstra et al. 2015).

We assume a discount rate of $\rho=0.06$, and a depreciation rate of $\delta=0.06$, and $\sigma=2$, corresponding to an (asymptotic) elasticity of intertemporal substitution of 0.5 . With the exception of the discount rate, these are standard values in the literature. We choose a high discount rate partly because this seems appropriate for a developing country, and will examine sensitivity to this assumption later in the paper.

The intratemporal Stone-Geary preferences have two parameters: the asymptotic food expenditure share $\gamma$ and the subsistence parameter $q$. We select $\gamma=0.20$ which is the food 
share for South Africa in FAO data. For $q$, we use an iterative procedure to ensure that, in our benchmark economy, the initial budget share for food matches the median value in FAO data (various years), namely $0.51 .^{9}$

For the agricultural production function, we adopt the output elasticities estimated by Martin and Mitra (2001) for their Cobb-Douglas, constant returns to scale case. They estimate an output-capital elasticity of 0.12 , an output-land elasticity of 0.24 , and hence an output-labour elasticity of 0.64 . These are also the parameters used for agricultural production in Irz and Roe (2005). ${ }^{10}$

For the elasticity of substitution between capital and labour in non-agriculture, the survey by Chirinko (2008) argues that the weight of evidence for the whole US economy favours 0.40 to 0.60 , while the meta-regression in Knoblach et al. (2019) gives a range of $0.45-0.87$ for the US economy, and indicates that estimates for industry would be similar. With these findings in mind, we adopt $\sigma_{K L}=0.60$. We calibrate the distribution parameter in the CES technology so that the steady-state capital share for the sector (and the asymptotic share for the economy as a whole) will be equal to 0.30 . As we will see later, this assumption plays a key role in the analysis.

The sectoral rates of labour-augmenting technical progress will be important in determining the rate of structural change. We set $g_{a}$ to 0.020 and $g_{m}$ to $0.010 .{ }^{11}$ Combined with our other assumptions, these values ensure a rate of structural change comparable to those in Table 1, as we discuss further below. Note that our parameter assumptions ensure that (17) holds, as required for asymptotic balanced growth. That can be achieved even when the rate of technical progress in agriculture exceeds that in non-agriculture. This is because other forces - capital accumulation, and labour force growth in the context of fixed land — work to increase the non-agricultural sector's share in value added. ${ }^{12}$

In the version of the Stone-Geary economy that we consider, technical progress eventually renders the subsistence parameter $q$ irrelevant. The balanced growth path is asymptotic, as in one-sector models with Stone-Geary preferences; see, for example, Ohanian et al. (2008).

For the initial capital-output ratio, we use a figure of 1.23 , based on calculations for low-income aid recipients in Carter et al. (2015). ${ }^{13}$ Under our assumptions, the steady-state capital-output ratio in the benchmark economy is 2.50 . This implies that the capital-output

\footnotetext{
${ }^{9}$ The iterative procedure is needed because computing the initial budget share requires knowledge of initial consumption expenditure, which can be established only by solving numerically the system of dynamic equations.

${ }^{10}$ In practice the parameters are likely to vary across countries (Eberhardt and Teal 2013a). Vollrath (2011) and Eberhardt and Vollrath (2018) find that structural transformation and development patterns are sensitive to the output-labour elasticity in agriculture, corresponding to different crop types; we intend to explore this in further work.

${ }^{11}$ The figure for efficiency growth in agriculture may seem high, but TFP growth in sub-Saharan Africa has increased since the early 1980s (Block 2014).

${ }^{12}$ The interaction of fixed land and growing population in driving structural transformation was previously noted in Ying (2014).

${ }^{13}$ They used a perpetual inventory calculation based on investment and output data from the Penn World Table. Their calculation assumed a one-sector economy, but there is no straightforward way to generalize this to our two-sector setting.
} 
ratio in our benchmark economy will roughly double in the course of converging to the steady-state; for comparison, Obstfeld (1999) studied a three-fold increase.

To carry out the simulations, we use the relaxation algorithm of Trimborn et al. (2008). This algorithm allows us to solve for the paths of all variables in the system of equations, without the need for the approximations around the steady-state that were used in Obstfeld (1999) and related papers. This is a particular gain when we consider models where convergence to the steady-state is slow, as will sometimes arise given Stone-Geary preferences and a multi-sector structure. Atolia et al. (2010) emphasize the relevance of the convergence speed, and note that the errors introduced into growth models by linearization can be especially important for welfare calculations.

Our assumptions imply that structural change continues indefinitely, with the share of the agricultural sector in total employment approaching zero asymptotically. The growth rate of GDP per capita will asymptotically approach the rate of efficiency growth in nonagriculture, $g_{m}$. When solving the system of equations numerically, we convert the system into quantities measured in efficiency units: capital, sectoral outputs, total output and consumption are divided by the level of efficiency in the non-agricultural sector. Also note that in the associated system the subsistence parameter $q$ will also be rewritten in terms of efficiency units. Although $q$ is assumed constant, its normalized version declines over time: technical progress gradually renders the subsistence parameter irrelevant.

\section{Simulation results}

In what follows, we consider three cases. These are the benchmark, the effect of a permanent step increase in agricultural TFP $\left(X_{a}\right)$ of $10 \%$, and the effect of a permanent step increase in non-agricultural TFP $\left(X_{m}\right)$ of $10 \%$. These step increases in TFP can be thought of as a simple reduced-form for the effects of sector-specific government policies. For example, productivity in either sector could be a direct function of government-provided infrastructure. The government then has a choice over whether to invest in rural or urban infrastructure.

We first look at the paths of the agricultural employment share, which are shown in Figure 4a. The solid line is the baseline case, the dashed line arises under a step gain in agricultural productivity, and the dot-dashed line arises under a step gain in non-agricultural productivity. Note that, since we have assumed intersectoral labour mobility is costless, any shock to productivity at time zero results in an immediate change in the employment share at time zero.

In Figure 4b, we plot the logarithms of the agricultural employment shares. Beyond the first ten years, these are roughly straight downward-sloping lines, suggesting that the model can match the geometric decline in the agricultural employment share that we saw in the data. In the baseline case, the average rate of geometric decline $(100 \eta)$ is 1.33 , which would place this economy fifth among the ASD countries listed in Table $1 .^{14}$

\footnotetext{
${ }^{14}$ Note that this measures the rate of geometric decline over the 60 -year span shown in the figures. A
} 
Next, we look at the path of capital-output ratios, shown as the upper panel in Figure 5. At time zero, productivity improvements cause the initial capital-output ratio to fall, because the initial capital stock is fixed but output has increased. An agricultural productivity improvement does not promote aggregate capital accumulation, because the change in technology leads the agricultural sector to expand and it is less capital-intensive than non-agriculture. In the case of a non-agricultural productivity improvement, it is the nonagricultural sector which expands faster, the marginal product of capital increases, and capital is accumulated more rapidly than in the baseline case. The faster accumulation of capital drives faster wage growth, which can be seen in the lower panel of Figure 5.

The path of saving rates is shown in the upper panel of Figure 6 . The benchmark rate is comparable to the gross investment rates of $15-19 \%$ in sub-Saharan Africa that are documented in Melina and Portillo (2018, Table 5). The effect of a non-agricultural TFP gain on the demand for capital causes a higher saving rate in that case. But the response is muted, and it is also noticeable that the saving rates do not show the initial spike that often appears in the one-sector Ramsey model. In this two-sector model with Stone-Geary intratemporal preferences, the presence of subsistence consumption of the agricultural good keeps initial saving relatively low. There is still a peak in the initial growth rate, as in the lower panel of Figure 6, but this is again muted relative to the one-sector case. ${ }^{15}$ In the case of the agricultural productivity improvement, the growth rate is stable given the slower accumulation of capital in this case.

The effect of a TFP gain is to increase lifetime welfare. Starting from our benchmark economy, a $10 \%$ increase in agricultural TFP has the same effect on lifetime utility as increasing consumption expenditure by $5.9 \%$ along the benchmark path (all welfare effects will be reported to one decimal place). A $10 \%$ increase in non-agricultural TFP has the same effect as increasing consumption expenditure by $7.6 \%$ along the benchmark path. Although non-agriculture initially accounts for a lower share of employment, it is expanding over time, and this means that productivity improvements in non-agriculture are more valuable than those in agriculture.

The precise extent of the difference is sensitive to the capital intensity of the nonagricultural sector. The higher that intensity, the more sensitive is sectoral structure to the accumulation of capital. ${ }^{16}$ If we calibrate the distribution parameter of non-agriculture's CES production function so that the steady-state capital share is 0.35 rather than 0.30 , the case for prioritizing non-agriculture strengthens. In this new economy, a $10 \%$ increase in agricultural TFP is equivalent to increasing consumption expenditure by $4.6 \%$ along the benchmark path. In contrast, a 10\% increase in non-agricultural TFP has the same effect on welfare as increasing consumption expenditure by $9.4 \%$ along the benchmark path. ${ }^{17}$

calculation based on a shorter interval would sometimes show a faster rate of structural transformation, as is evident from Figure $4 b$.

${ }^{15}$ For the one-sector case see, for example, Barro and Sala-i-Martin (2004, pp. 116-118).

${ }^{16}$ Acemoglu and Guerrieri (2008) emphasized the role of sectoral differences in factor proportions in shaping structural transformation and aggregate growth.

${ }^{17}$ It might seem surprising that the consumption-equivalent welfare gain from a sector-specific TFP shock 
One way to increase the priority of agriculture would be to consider a slower rate of structural transformation. If we consider the benchmark economy but reduce $g_{a}$ to 0.015 and $g_{m}$ to 0.005 , this reduces the pace of structural transformation. In this new setting, the average rate of geometric decline of the agricultural employment share falls to $100 \eta=1.09$, compared to 1.33 earlier. But a comparison of welfare effects still favours non-agriculture. A $10 \%$ increase in agricultural TFP is equivalent to increasing nominal consumption expenditure by $5.8 \%$ along the baseline path. In contrast, a $10 \%$ increase in non-agricultural TFP has the same effect on welfare as increasing consumption expenditure by $7.9 \%$ along the baseline path.

Another way to slow down the structural transformation is to assume that profits are taxed in both sectors, at a common rate $\tau$. This could be interpreted as a formal tax, or the outcome of corruption and otherwise imperfect institutions, such as a risk of expropriation. To introduce a capital tax we can modify (11) to:

$$
\frac{\dot{\lambda}}{\lambda}=\rho-(1-\tau)\left(f^{\prime}\left(k_{m}\right)-\delta\right)
$$

which assumes that depreciation is tax deductible. ${ }^{18}$ As in the standard one-sector analysis, the introduction of a capital tax reduces steady-state capital intensity and the rate of capital accumulation. In our two-sector case, this slows down structural transformation. Given our broad interpretation of the tax we choose a high value, $\tau=0.40$. Under that assumption, the average rate of geometric decline of the agricultural employment share falls to $100 \eta=0.51$, compared to 1.33 in the benchmark case. This would put the economy in seventh place in Table 1, but leads to gross investment rates in the region of $10 \%$ of GDP, which are lower than the rates in Melina and Portillo (2018).

Not surprisingly, the slower rate of structural transformation brings the welfare effects closer together. We find that a $10 \%$ increase in agricultural TFP has the same effect on welfare as increasing nominal consumption expenditure by $6.6 \%$ along the baseline path. This is only slightly lower than the welfare gain from a non-agricultural TFP improvement, which has the same effect as increasing consumption expenditure by $6.8 \%$.

A final way to increase the priority of agriculture is to increase the discount rate. As mentioned in the introduction, this favours agriculture in two ways. First, by giving more weight in the welfare calculation to near-term outcomes, it gives more weight to times when agriculture accounts for a high share of employment. Second, a higher discount rate greater impatience - leads households to save less. The slower rate of capital accumulation means slower structural transformation, again tipping the balance towards agriculture. With a discount rate of $\rho=0.08$, we find that a $10 \%$ increase in agricultural TFP has the same effect on welfare as increasing consumption expenditure by $6.9 \%$ along the baseline path. This is larger than the welfare gain from a non-agricultural TFP improvement, which has the

is so large, but recall that consumption is lower than output.

${ }^{18}$ For the relevant assumptions see, for example, Barro and Sala-i-Martin (2004, pp. 144-145). For simplicity, we assume that the proceeds of the tax are reimbursed to households as a lump sum, so the capital accumulation equation is unchanged. 
same effect as increasing consumption expenditure by $6.4 \%$. In the baseline case (without a productivity gain) the implied investment rate increases from $11 \%$ at time zero to $18 \%$ along the asymptotic balanced growth path. Hence, investment is initially lower than the rates seen in the data.

\section{Conclusion}

In this paper we have described a tractable two-sector, three-factor dynamic model of a small open economy, close to the models used in Roe et al. (2010). The model can be used to study structural transformation arising from sector-specific technical progress and capital accumulation. It gives rise to an asymptotic balanced growth path without the need for restrictive knife-edge assumptions. We have described a simple solution procedure, and used the model to cast some light on development priorities.

In particular, we quantify the welfare gains from sector-specific productivity improvement, and examine how they vary across different scenarios. An advantage of an explicit welfare calculation is that we take into account foregone consumption, rather than emphasizing only aggregate growth effects. Our main finding is that, when a country is undergoing structural transformation, it matters whether an assessment of priorities is forward-looking. Although agriculture is initially the largest sector in terms of employment, we often find that step gains in non-agricultural productivity are more beneficial than step gains in agriculture.

This result continues to hold even when sector-specific rates of technical progress are slow. In our simulations, capital accumulation contributes to a fast rate of structural transformation. Assuming a higher discount rate slows down capital accumulation, and this can tip the welfare calculation to favour productivity gains in agriculture. This is also true of taxes on profits, reflecting the formal tax system, or perhaps corruption and other forms of institutional weakness. The model is simple enough that it could readily be extended in many other directions.

\section{References}

[1] Acemoglu, D. (2009). Introduction to Modern Economic Growth. Princeton University Press, Princeton.

[2] Acemoglu, D. and Guerrieri, V. (2008). Capital Deepening and Nonbalanced Economic Growth. Journal of Political Economy, 116(3), 467-498.

[3] Alder, S., Boppart, T. and Müller, A. (2019). A Theory of Structural Change that Can Fit the Data. CEPR discussion paper 13469.

[4] Alonso-Carrera, J. and Raurich, X. (2015). Demand-based structural change and balanced economic growth. Journal of Macroeconomics, 46, 359-374. 
[5] Atolia, M., Chatterjee, S. and Turnovsky, S. J. (2010). How misleading is linearization? Evaluating the dynamics of the neoclassical growth model. Journal of Economic Dynamics and Control, 34, 1550-1571.

[6] Attanasio, O. P. and Browning, M. (1995). Consumption over the life cycle and over the business cycle. American Economic Review, 85(5), 1118-1137.

[7] Barro, R. J. and Sala-i-Martin, X. (2004). Economic Growth. MIT Press, Cambridge, MA.

[8] Ben-David, D. (1998). Convergence clubs and subsistence economies. Journal of Development Economics 55(1), 155-171.

[9] Bertola, G., Foellmi, R. and Zweimüller, J. (2006). Income distribution in macroeconomic models. Princeton University Press, Princeton.

[10] Bliss, C. (2007). Trade, growth, and inequality. Oxford University Press, Oxford.

[11] Bliss, C. (2008). The elasticity of intertemporal substitution. In S. N. Durlauf and L. E. Blume (eds.) The New Palgrave Dictionary of Economics (second edition). Palgrave Macmillan, 2008.

[12] Block, S. (2014). The post-independence decline and rise of crop productivity in subSaharan Africa: measurement and explanations. Oxford Economic Papers, 66, 373-396.

[13] Blundell, R., Browning, M. and Meghir, C. (1994). Consumer demand and the life-cycle allocation of household expenditures. Review of Economic Studies, 61(1), 57-80.

[14] Carter, P., Postel-Vinay, F. and Temple, J. R. W. (2015). Dynamic aid allocation. Journal of International Economics, 95(2), 291-304.

[15] Chirinko, R. S. (2008). $\sigma$ : The long and short of it. Journal of Macroeconomics, 30, 671-686.

[16] Christiano, L. J. (1989). Understanding Japan's saving rate: the reconstruction hypothesis. Federal Reserve Bank of Minneapolis Quarterly Review, 13(2), 10-19.

[17] Connolly, M. and Yi, K.-M. (2015). How much of South Korea's Growth Miracle can be explained by trade policy? American Economic Journal: Macroeconomics, 7(4), 188-221.

[18] Crossley, T. F. and Low, H. W. (2011). Is the elasticity of intertemporal substitution constant? Journal of the European Economic Association, 9(1), 87-105.

[19] Cuñat, A. and Maffezzoli, M. (2004). Neoclassical growth and commodity trade. Review of Economic Dynamics, 7(3), 707-736. 
[20] Dercon, S. and Gollin, D. (2014). Agriculture in African development: theories and strategies. Annual Review of Resource Economics, 6, 471-492.

[21] Eberhardt, M. and Teal, F. (2013a). No Mangoes in the Tundra: Spatial Heterogeneity in Agricultural Productivity Analysis. Oxford Bulletin of Economics and Statistics, 75(6), 914-939.

[22] Eberhardt, M. and Teal, F. (2013b). Structural Change and Cross-Country Growth Empirics. World Bank Economic Review, 27(2), 229-271.

[23] Eberhardt, M. and Vollrath, D. (2018). The effect of agricultural technology on the speed of development. World Development, 109, 483-496.

[24] Feenstra, R. C. (2004). Advanced international trade. Princeton University Press, Princeton.

[25] Feenstra, R. C., Inklaar, R. and Timmer, M. P. (2015). The Next Generation of the Penn World Table. American Economic Review, 105(10), 3150-3182.

[26] Felice, G. (2016). Size and composition of public investment, sectoral composition and growth. European Journal of Political Economy, 44, 136-158.

[27] Foster, A. D. and Rosenzweig, M. R. (2008). Economic development and the decline of agricultural employment. In T. Schultz J. Strauss (eds.) Handbook of Development Economics, Volume 4, Elsevier.

[28] Gollin, D. (2010). Agricultural productivity and economic growth. In R. E. Evenson and P. L. Pingali (eds.) Handbook of Agricultural Economics, Volume 4, Elsevier.

[29] Gollin, D., Parente, S. L. and Rogerson, R. (2007). The food problem and the evolution of international income levels. Journal of Monetary Economics, 54, 1230-1255.

[30] Hayashi, F. and Prescott, E. C. (2008). The depressing effect of agricultural institutions on the prewar Japanese economy. Journal of Political Economy, 116(4), 573-632.

[31] Irz, X and Roe, T. (2005). Seeds of growth? Agricultural productivity and the transitional dynamics of the Ramsey model. European Review of Agricultural Economics, 32(2), 143-165.

[32] King, R. G. and Rebelo, S. T. (1993). Transitional dynamics and economic growth in the neoclassical model. American Economic Review, 83(4), 908-931.

[33] Knoblach, M., Roessler, M. and Zwerschke, P. (2019). The Elasticity of Substitution Between Capital and Labour in the US Economy: A Meta-Regression Analysis. Oxford Bulletin of Economics and Statistics, forthcoming.

[34] Kongsamut, P., Rebelo, S. and Xie, D. (2001). Beyond balanced growth. Review of Economic Studies, 68, 869-882. 
[35] Kraay, A. and Raddatz, C. (2007). Poverty traps, aid, and growth. Journal of Development Economics, 82(2), 315-347.

[36] Leamer, E. E. (1987). Paths of Development in the Three-Factor, n-Good General Equilibrium Model. Journal of Political Economy, 95(5), 961-999.

[37] Lewis, W. A. (1953). Report on industrialisation and the Gold Coast. Accra, Govt. Print. Dept.

[38] Martin, W. and Mitra, D. (2001). Productivity convergence in agriculture versus manufacturing. Economic Development and Cultural Change, 49(2), 403-422.

[39] Mason, N. M., Jayne, T. S., Donovan, C. and Chapoto, A. (2011). Are staple foods becoming more expensive for urban consumers in eastern and southern Africa? Trends in food prices, marketing margins and wage rates in Kenya, Malawi, Mozambique, and Zambia. In Lee, D. R. and Ndulo, M. (eds.) The food and financial crises in sub-Saharan Africa: origins, impacts and policy implications. Cambridge, MA: CABI.

[40] Matsuyama, K. (1992). Agricultural productivity, comparative advantage, and economic growth. Journal of Economic Theory, 58(2), 317-334.

[41] McMillan, M. and Rodrik, D. (2012). Globalization, structural change, and productivity growth. IFPRI discussion papers 1160, International Food Policy Research Institute.

[42] Melina, G. and Portillo, R. (2018). Economic Fluctuations in sub-Saharan Africa. IMF working paper no. $18 / 40$.

[43] Mosley, P. and Ingham, B. (2013). Sir Arthur Lewis: a Biography. Houndmills, Basingstoke, Hampshire: Palgrave Macmillan.

[44] Mundlak, Y. and Larson, D. F. (1992). On the transmission of world agricultural prices. World Bank Economic Review, 6(3), 399-422.

[45] Ngai, L. R. and Pissarides, C. A. (2004). Structural change in a multisector model of growth. American Economic Review, 97(1), 429-443.

[46] Obstfeld, M. (1999). Foreign resource inflows, saving, and growth. In K. SchmidtHebbel and L. Serven (eds.), The economics of saving and growth. Cambridge University Press, Cambridge.

[47] Ohanian, L., A. Raffo, and R. Rogerson (2008). Long-term changes in labour supply and taxes: Evidence from OECD countries, 1956-2004. Journal of Monetary Economics, 55(8), 1353-1362.

[48] Rebelo, S. (1992). Growth in open economies. Carnegie-Rochester Conference Series on Public Policy, 36, 5-46. 
[49] Robertson, P. E. (1999). Economic Growth and the Return to Capital in Developing Economies. Oxford Economic Papers, 51(4), 577-94.

[50] Roe, T. L., Smith, R. B. W. and Saracoğlu, D. S. (2010). Multisector growth models: theory and application. Springer, New York.

[51] Sachs, J. D. (2005). The End of Poverty. Penguin, New York.

[52] Schelkle, Thomas (2014). Accounting for Convergence between Countries. Manuscript, University of Cologne.

[53] Steger, T. M. (2009). Economic growth with subsistence consumption. Journal of Development Economics, 62(2), 343-361.

[54] Święcki, T. (2017). Determinants of structural change. Review of Economic Dynamics, 24, 95-131.

[55] Trimborn, T., K.-J. Koch, and T. M. Steger (2008). Multidimensional transitional dynamics: a simple numerical procedure. Macroeconomic Dynamics, 12, 301-319.

[56] Uy, T., Yi, K.-M., Zhang, J. (2013). Structural change in an open economy. Journal of Monetary Economics, 60, 667-682.

[57] Ventura, J. (1997). Growth and Interdependence. Quarterly Journal of Economics, 112(1), 57-84.

[58] Ventura, J. (2005). A Global View of Economic Growth. In P. Aghion and S. N. Durlauf (eds.) Handbook of Economic Growth, Volume 1, pp. 1419-1497, Elsevier.

[59] Vollrath, D. (2011). The agricultural basis of comparative development. Journal of Economic Growth, 16, 343-370.

[60] de Vries, Gaaitzen, Timmer, Marcel and de Vries, Klaas (2015). Structural Transformation in Africa: Static Gains, Dynamic Losses. Journal of Development Studies, 51(6), 674-688.

[61] Wingender, A. M. (2015). Skill complementarity and the dual economy. European Economic Review, 74, 269-285.

[62] Ying, H. (2014). Growth and Structural Change in a Dynamic Lagakos-Waugh Model. Bristol Economics Discussion Papers 14/639, Department of Economics, University of Bristol. 
Figure 4: Agricultural employment

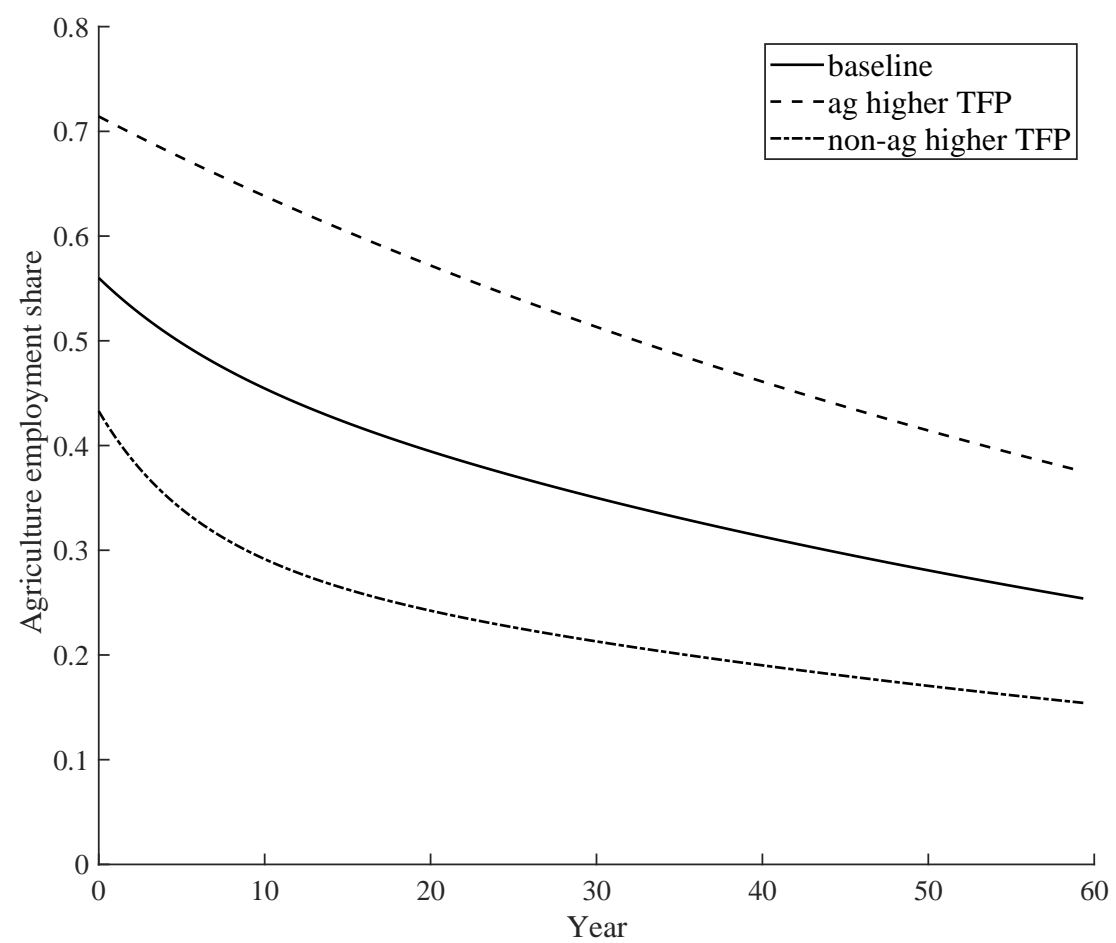

(a) Agricultural employment share

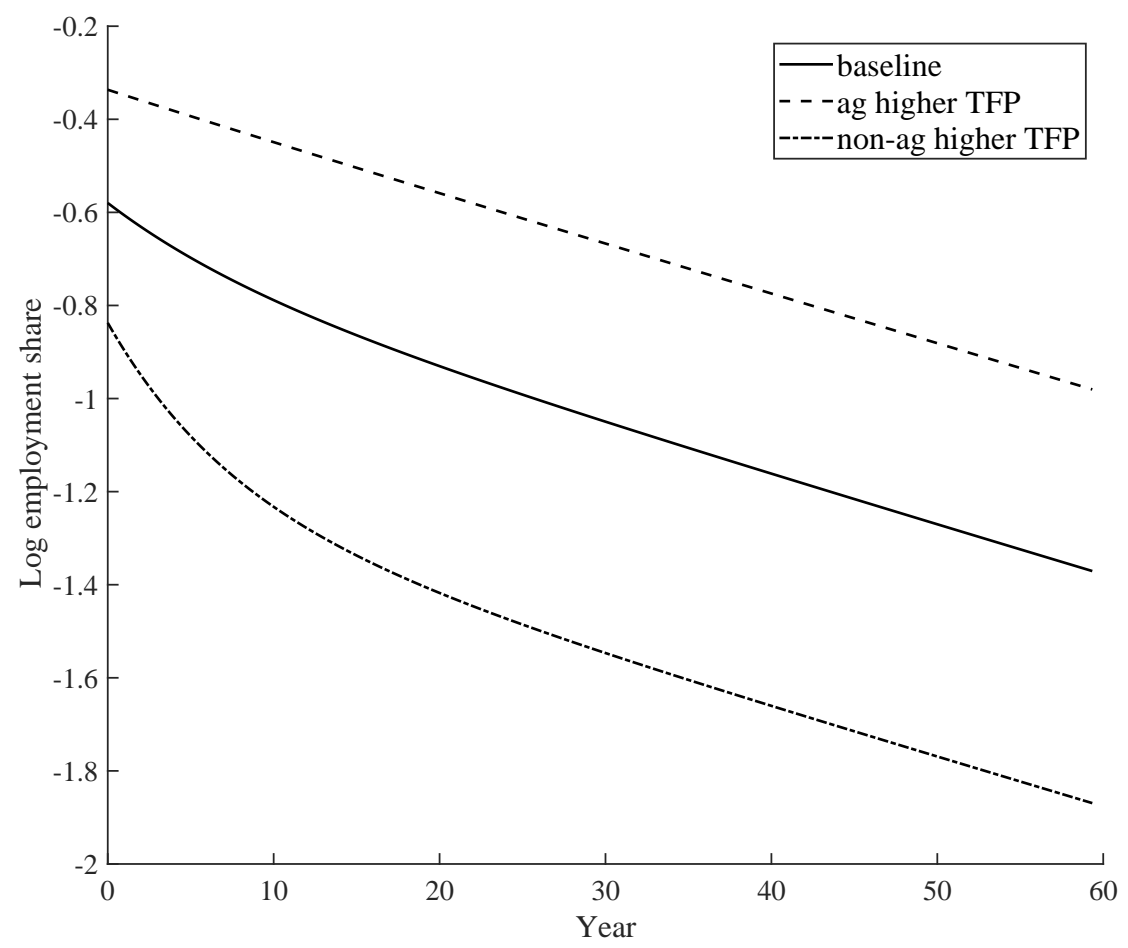

(b) Log agricultural employment share 
Figure 5: Capital and wages

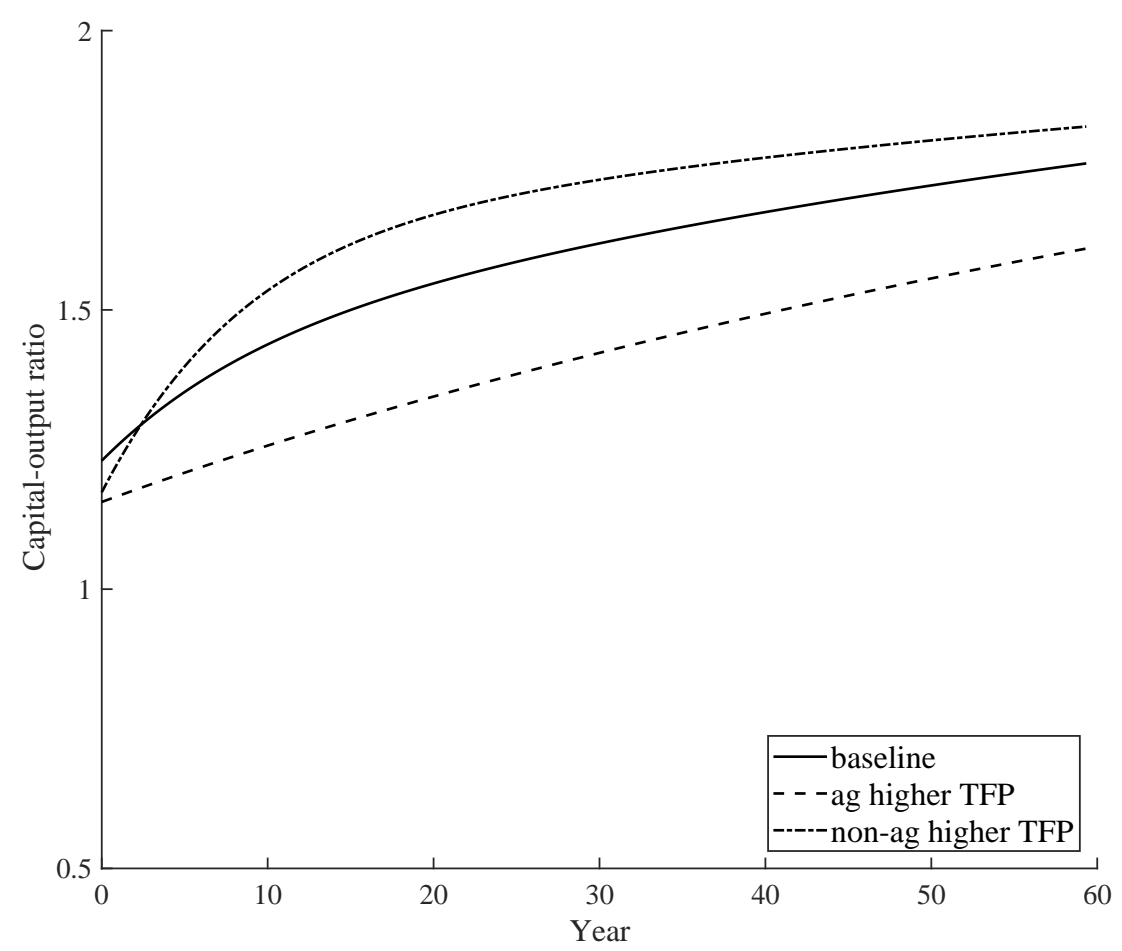

(a) Capital-output ratios

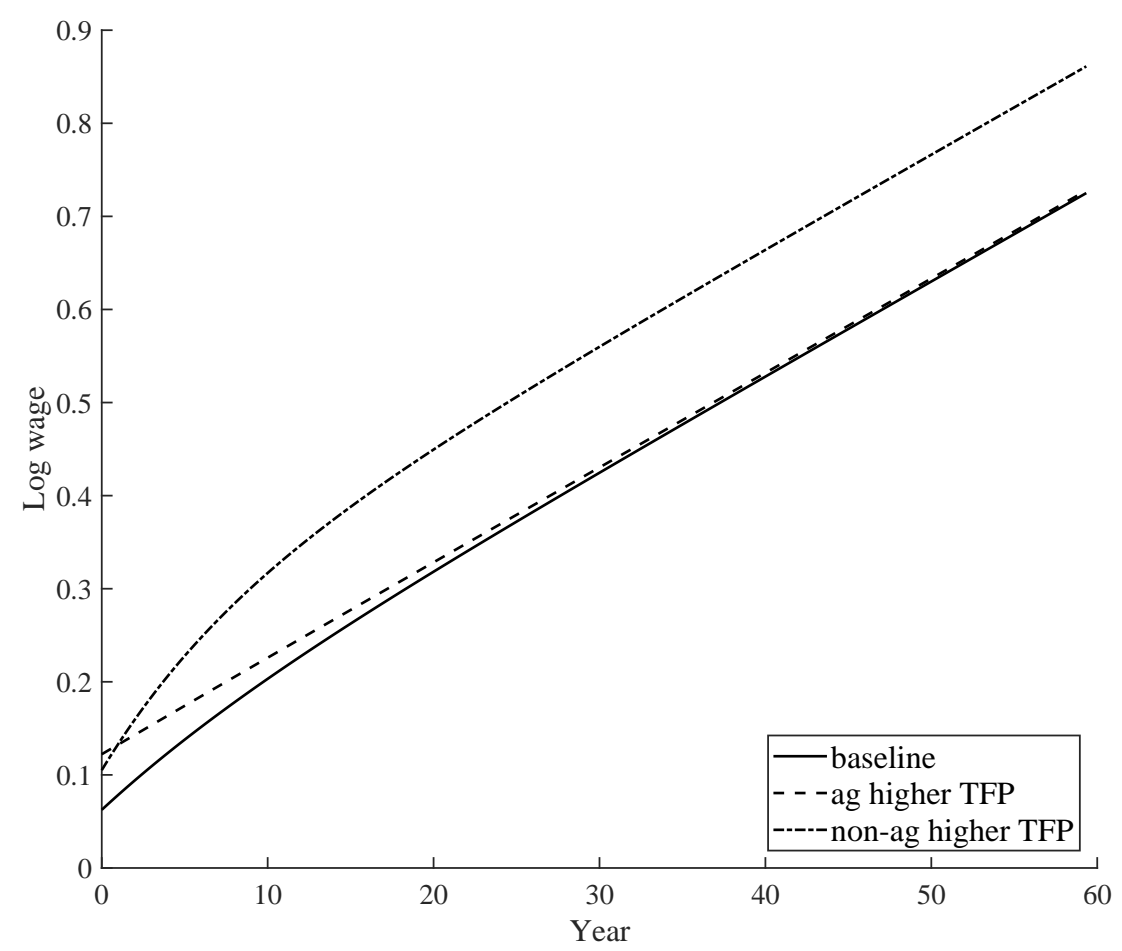

(b) Log wages 
Figure 6: Saving rates and growth rates

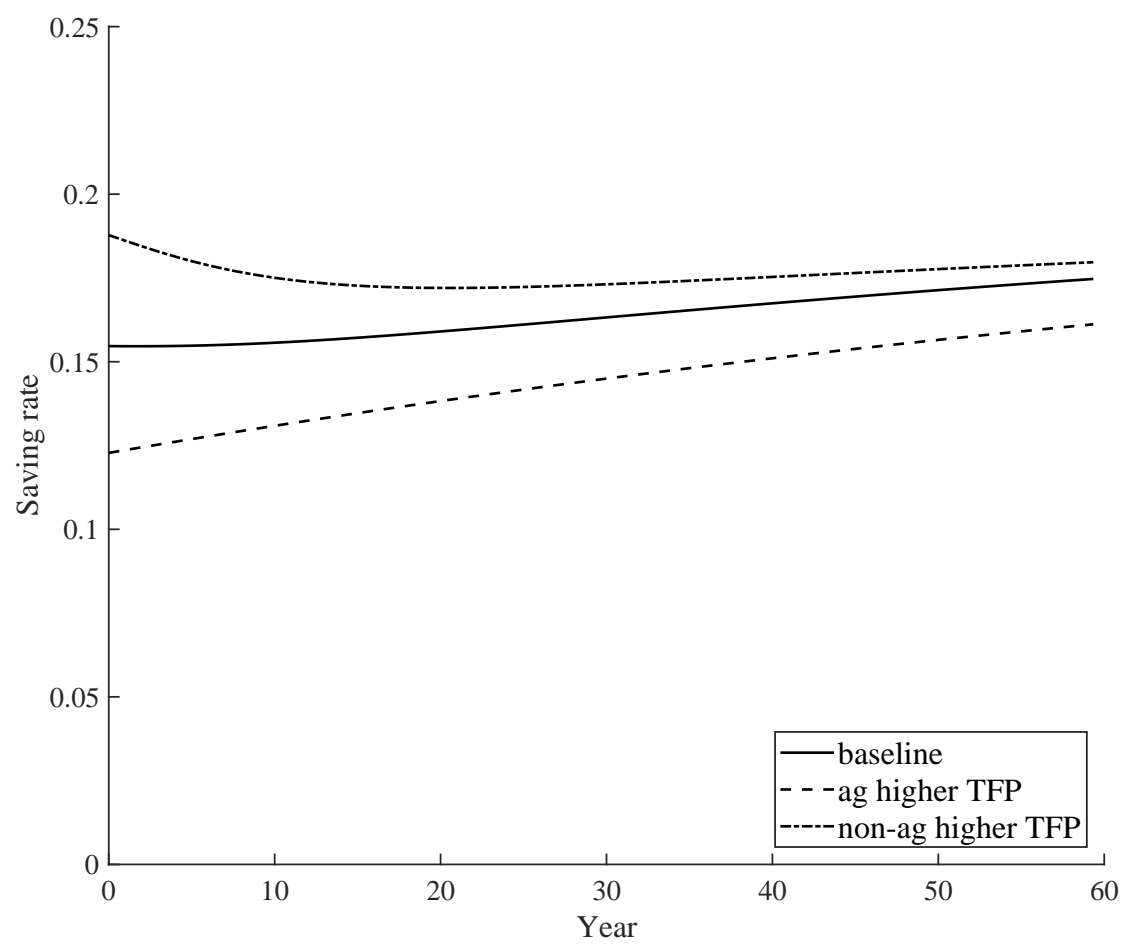

(a) Saving rates

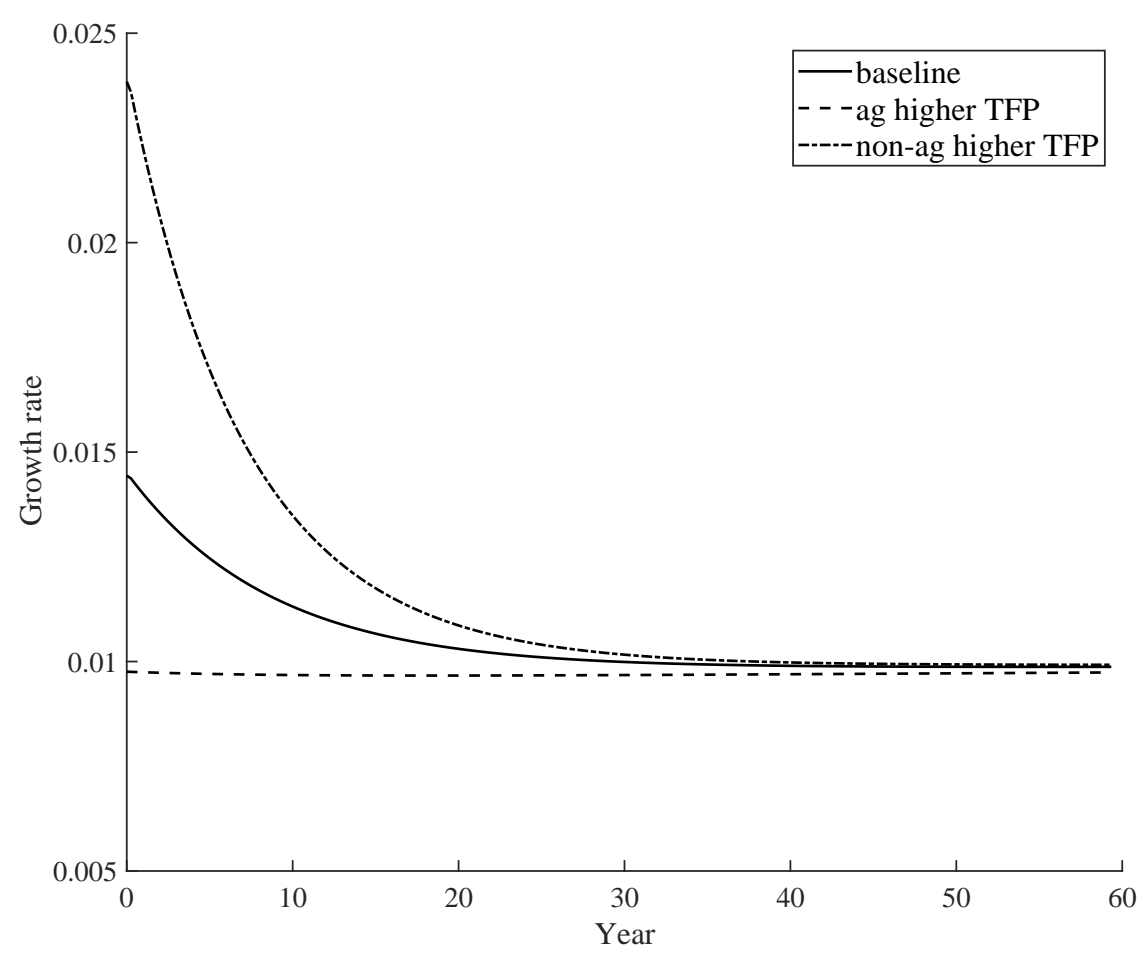

(b) Annual growth rates 